\title{
Metformin induced acute kidney injury; a systematic review
}

\author{
Mahnaz Momenzadeh $^{1^{*} \mathbb{(}}$, Bhaskar VKS Lakkakula $^{(\mathbb{D}}$ \\ ${ }^{1}$ Department of Clinical Pharmacy and Pharmacy Practice, Faculty of Pharmacy and Pharmaceutical Sciences, Isfahan University of \\ Medical Sciences, Isfahan, Iran \\ ${ }^{2}$ Department of Zoology, Guru Ghasidas Vishwavidyalaya, Bilaspur, India
}

\section{A R T I C L E IN F O}

Article Type:

Review

\section{Article History:}

Received: 17 June 2020

Accepted: 30 August 2020

Published online: 9 September 2020

\section{Keywords:}

Acute kidney injury

Type 2 diabetes mellitus

Metformin

Glomerular filtration rate

\begin{abstract}
A B S T R A C T
Introduction: Metformin is the best proven first-line treatment for type 2 diabetes (T2DM), based on both national and international guidelines. The present systematic review is aimed to examine the acute kidney injury (AKI) risk associated with metformin.

Methods: A systematic literature search was performed in MEDLINE, PubMed and google scholar, to retrieve the literature related to the metformin use. A bibliographic management software (Endnote X9) was used for managing the literature. The following keywords were used: "Acute renal injury OR ARI”, “Acute kidney injury OR AKI”," Metformin”, “ Type 2 diabetes mellitus OR T2DM", "Diabetic patients", "Renal function", "CKD”.

Results: About 28 relevant articles were found during the electronic and manual search. Finally, a total of four articles that fulfill the inclusion criteria were used for this systematic literature review. There is no evidence to suggest that metformin increases the incidence of AKI and is associated with an increased survival of 28 days following AKI event. Further, there was no difference in the incidence of AKI in patients who continued metformin after arterial contrast exposure compared with the control group.

Conclusion: In summary, there is no evidence that metformin increases the incidence of AKI. More clinical trials are needed in this area, to investigate more evidence so that we can better understand the outcome.
\end{abstract}

Implication for health policy/practice/research/medical education:

There is no evidence that metformin increases incidence of acute kidney injury.

Please cite this paper as: Momenzadeh M, Lakkakula BVKS. Metformin induced acute kidney injury; a systematic review. J

Nephropharmacol. 2021;10(2):e13. DOI: 10.34172/npj.2021.13.

\section{Introduction}

Type 2 diabetes mellitus (T2DM) is a chronic condition, long-term T2DM can leads to both microvascular and macrovascular complications (1). The advancement of kidney disease is related to poor controlled T2DM and other complications (2). Hence, preventing kidney disease and abating the progression of kidney disease is one point of therapy (3). It has been hypothesized that the drugs used to treat T2DM play a major role in protecting the kidneys by regulating blood sugar levels and may have extra-protective effects according to particular drug profiles (4). Metformin is used in T2DM to reduce the amount of glucose produced by the liver and to enhance the body's response to insulin secreted by the pancreas. The mean renal clearance of metformin is diminished in patients with renal failure (acute or chronic), leading to lactic acidosis, which is associated with a mortality rate of $50 \%(5,6)$. Having a half-life of about $4-8$ hours, $90 \%$ of metformin is eliminated via renal excretion, in the setting of normal kidney function. Although metformin is not directly associated with nephrotoxicity, it has been suggested that the metformin can inhibit gluconeogenic pathway of lactate metabolism resulting to lactate accumulation in conditions such as acute renal failure (7). In any case, as kidney function interrupt, treatment choices for T2DM become restricted due to prescribing limitations $(8,9)$. Following the FDA's announcement, the European Medicines Agency (EMA) also recently reported that metformin-containing drugs may be used in patients with moderately impaired kidney function (eGFR 30 to $59 \mathrm{~mL} / \mathrm{min}$ per $1.73 \mathrm{~m}^{2}$ ) (1). However, serum creatinine levels allow the detection of mild AKI (stage 
1) without relying on clinic coding systems that allow for the assessment of renal safety in chronic kidney disease (CKD) patients. In this systematic review, we investigated whether metformin was associated with an increased risk of acute kidney injury (AKI).

\section{Methods}

\section{Search strategy}

A systematic literature search was performed in PubMed, Scopus and Google Scholar, to retrieve the literature related to the metformin use. A bibliographic management software (Endnote X9) was used for managing the literature. The following keywords were used in different combinations: "Acute Renal injury OR ARI", "Acute kidney injury OR AKI", "Metformin", “ Type 2 diabetes mellitus OR T2DM", "Diabetic patients", "Renal function", “CKD”, "contrast induced nephropathy OR CIN".

\section{Selection criteria}

Inclusion criteria

Prospective and retrospective cohort studies in humans, randomized controlled trials (RCT), controlled clinical trials (CCTs) related to metformin use in AKI or T2DM patients with AKI were included in this study.

\section{Exclusion criteria}

In vitro studies, case reports, animal experiments, reviews and case control studies were all excluded.

\section{Data Extraction and method of analysis}

Data of each selected study was extracted including; study, years, study design, sample size, range and mean of age, glomerular filtration rate, lactic acidosis, incidence of AKI/
CIN, outcome. Because of heterogeneity in information, meta-analysis studies were not included.

\section{Results}

About 28 relevant articles were found through the electronic and manual search. Based on title and abstract, 14 publications were excluded at the first stage of study selection. In the second phase, full text articles of 11 publications were fully evaluated. A final full-text reading, seven papers were excluded because their scopes were not related to the present review. Finally, a total of 4 publications were included in this systematic review (Figure 1). Table 1 shows the characteristics of individual studies used in this review.

As presented in Table 1, four studies (1 RCT, 1 retrospective study and 2 cohort studies) were included, with participants ranging from 10 to 25186 , with an average age of 68.12 years. In the study of Namazi et al (7), patients were randomly assigned to continue metformin during the peri-angiography period ( $\mathrm{M}(+)$ group) or advised to stop taking the medicine 24 hours prior to the angiography procedure (M (-) group). In all patients, iodixanol was used as a contrast agent during coronary angiography (CAG) and their glomerular filtration rate (GFR) was $>60 \mathrm{~mL} / \mathrm{min}$ per $1.73 \mathrm{~m}^{2}$. The presence of arterial $\mathrm{pH}$ $<7.35$ and plasma lactate level $>5 \mathrm{mmol} / \mathrm{L}$ was defined as metformin associated lactic acidosis (MALA). The results of this study indicated that there is no difference in the average GFR between two groups while no lactic acidosis was observed in the mentioned groups. Therefor this study suggests that metformin continuation may not increase the risk of MALA development in diabetic patients with GFR $>60 \mathrm{~mL} / \mathrm{min}$ per $1.73 \mathrm{~m}^{2}$. Study of Amos et al (10) is

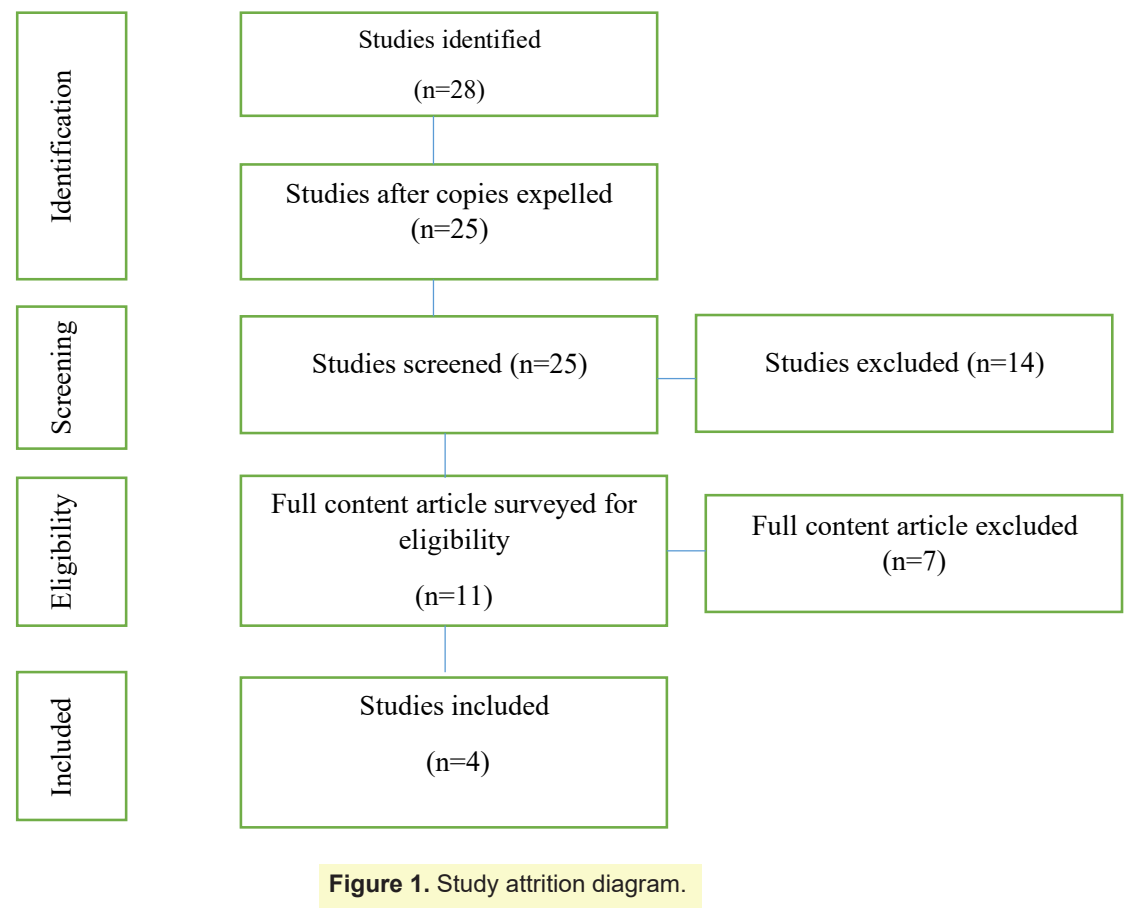




\begin{tabular}{|c|c|c|c|c|c|c|c|c|c|}
\hline \multirow{2}{*}{ Study/year } & \multirow{2}{*}{ Design } & \multicolumn{2}{|c|}{ Sample size } & \multirow{2}{*}{$\begin{array}{l}\text { Mean } \\
\text { age }\end{array}$} & \multirow{2}{*}{$\begin{array}{c}\text { GFR }(\mathrm{mL} / \\
\left.\mathrm{min} / 1.73 \mathrm{~m}^{2}\right)\end{array}$} & \multirow{2}{*}{ Lactic acidosis } & \multicolumn{2}{|c|}{ Incidence of $\mathrm{AKI} / \mathrm{CIN}$} & \multirow{2}{*}{ Outcome } \\
\hline & & $\begin{array}{l}\text { Intervention } \\
\text { group }\end{array}$ & $\begin{array}{l}\text { Control } \\
\text { group }\end{array}$ & & & & $\begin{array}{l}\text { Intervention } \\
\text { group }\end{array}$ & $\begin{array}{l}\text { Control } \\
\text { group }\end{array}$ & \\
\hline $\begin{array}{l}\text { Namazi et } \\
\text { al/2018 (7) }\end{array}$ & RCT & 166 & & 61.5 & eGFR >60 & $\begin{array}{l}\text { Lactic acidosis } \\
\text { was absent in the } \\
\text { studied groups }\end{array}$ & & & $\begin{array}{l}\text { Continuing Metformin in T2DM } \\
\text { patients with normal kidney } \\
\text { function and a GFR of }>60 \mathrm{~mL} / \\
\text { min per } 1.73 \mathrm{~m}^{2} \text {, performing } \\
\text { CAG, does not show higher risk } \\
\text { for MALA. }\end{array}$ \\
\hline $\begin{array}{l}\text { Amos, et } \\
\mathrm{al} / 2019(10)\end{array}$ & Retrospective & 67 & 87 & 65.81 & eGFR $\geq 30$ & $\begin{array}{l}\text { Lactic acidosis } \\
\text { was absent in the } \\
\text { studied groups }\end{array}$ & 9 & 7 & $\begin{array}{l}\mathrm{CIN} \text { or } \mathrm{AKI} \text { are defined as an as } \\
\text { absolute increase in creatinine by } \\
0.5 \mathrm{mg} / \mathrm{dL} \text { or }>25 \% \text { rise in serum } \\
\text { creatinine levels from baseline at } \\
48 \text { hours upon contrast exposure. }\end{array}$ \\
\hline $\begin{array}{l}\text { Bell et } \\
\text { al/2017(1) }\end{array}$ & Cohort study & 14,622 & 10,526 & 68.2 & eGFR $\geq 30$ & $\begin{array}{l}\text { Lactic acidosis } \\
\text { was absent in the } \\
\text { studied groups }\end{array}$ & 439 & 1717 & $\begin{array}{l}\text { Metformin has no averse effect } \\
\text { on survival in patients with AKI. }\end{array}$ \\
\hline $\begin{array}{l}\text { Greco et } \\
\mathrm{al} / 2019(11)\end{array}$ & Cohort study & 10 & & 77 & Non & Non & Non & Non & $\begin{array}{l}\text { In patients with MALA and AKI, } \\
\text { a } 16 \text {-h SLED using conventional } \\
\text { dialysis or CRRT machines, } \\
\text { effectively cleared the metformin. } \\
\text { However, due to post-SLED } \\
\text { rebound in serum metformin } \\
\text { levels, an additional dialysis is } \\
\text { required at the subsequent day in } \\
\text { the majority of patients. }\end{array}$ \\
\hline
\end{tabular}

a retrospective review of 154 patients (67 T2DM patients used metformin and 87 (31\% had T2DM) were not on metformin) who underwent emergency CAG procedure after exposure to contrast agent. In this study, AKI or CIN after contrast exposure was defined as an absolute increase in creatinine by $0.5 \mathrm{mg} / \mathrm{dL}$ or $>25 \%$ increase in serum creatinine levels from baseline at 48 hours after exposure to contrast agents respectively. Comparing the values at 48 hours after arterial contrast exposure showed no difference in CIN between the two groups $(P=0.29)$. Elevated serum creatinine levels may have inhibited the use of metformin in the control group.

Another study by Bell et al (1), is a retrospective study on 25148 patients with T2DM (14,622 were taking metformin and 10,526 were never on metformin) within the Tayside region of Scotland. In this study, AKI was defined based on the criteria for "Kidney Disease Improving Global Outcomes", with an increase in serum creatinine level of at least $26.5 \mu \mathrm{mol} / \mathrm{L}$ or an increase of $>150 \%$ from baseline for all hospital admissions. This study did not provide the evidence to suggest that metformin increases incidence of AKI and is associated with an increased survival of 28 days following AKI event. Additionally, Greco et al (11) conducted a study in ten consecutive patients with suspected MALA associated with AKI and hemodynamic instability, who admitted into an intensive care unit. Serial serum metformin levels, clinical variables and outcome data, were collected from all patients. All patients underwent a 16-hour sustained low-efficiency dialysis (SLED) session carried out with conventional dialysis or continuous renal replacement therapy machines, which effectively removed the metformin from these patients In addition, their pharmacokinetic model predicted a modest 4-hour post-SLED rebound in serum metformin levels of the majority of patients that was corrected by one more supplementary dialysis session on the subsequent day.

\section{Discussion}

Patients receiving iodinated contrast media prior to radiologic investigations has been related to an acute decline in renal function and is associated with the increased risk of lactic acidosis in patients receiving metformin treatment. The recurrence of contrast materialassociated nephropathy is assessed to range from $0.1 \%$ $13 \%$; while, preexisting renal insufficiency is recognized as an imperative factor. No known interaction exists between metformin and iodinated contrast media. In any case, acute renal failure is associated with metformin collection and subsequent lactic acidosis (12). MALA does not occur in all the metformin-treated patients with CIN development (13). In addition, the majority of studies showed that the lactic acidosis occurs in patients with serious comorbidities such as renal dysfunction, liver failure, sepsis and decompensated heart failure (14). In contrast to common perceptions, some studies did not 
provide a proof for increased incidence of AKI in patients who continued metformin in comparison to the control group (10). Further, metformin use was associated with 28 days increased survival after AKI event (1). Furthermore, in a multicenter RCT, no cases of lactic acidosis was found in group of patients accepting or ceasing metformin (15). A meta-analysis of 194 studies did not prove that the metformin treatment was associated with the elevated lactic acidosis risk (16).

There is no development of lactic acidosis or no difference in the average GFR between patients taking metformin and patients halted metformin before CAG procedure (7), indicates the need to revise previous recommendations regarding general cessation of metformin in these patients. Additionally, determination of metformin serum levels may be useful to guide the therapeutic dose when GFR is low as well as to diagnose the metformin induced lactic acidosis (17). It is also suggested to halt metformin use at the time of or before administration of contrast media, if eGFR $<30 \mathrm{~mL} / \mathrm{min} / 1.73 \mathrm{~m}^{2}$ (18). In addition, a single center observational study demonstrated that metformin therapy prior to elective CAG is safer in patients with preserved left ventricular ejection fraction of $>40 \%$ or even with mild renal dysfunction (19). Likewise, in diabetic patients receiving metformin, no CIN has been reported after fundus fluorescein angiography (FFA) using fluorescein sodium (20).

\section{Conclusion}

In summary, there is no evidence that metformin increases the incidence of AKI. Further clinical trials are needed in this area, to investigate further evidence so that we can better understand the outcome.

\section{Authors' contribution}

MM was the principal investigator of the study. MM and BVKSL were included in preparing the concept and design. MM revised the manuscript and critically evaluated the intellectual contents. All authors participated in preparing the final draft of the manuscript, revised the manuscript and critically evaluated the intellectual contents. All authors have read and approved the content of the manuscript and confirmed the accuracy or integrity of any part of the work.

\section{Conflicts of interest}

The authors declare that they have no competing interests.

\section{Ethical considerations}

Ethical issues (including plagiarism, data fabrication, double publication) have been completely observed by the authors.

\section{Funding/Support}

None.

\section{References}

1. Bell S, Farran B, McGurnaghan S, McCrimmon RJ, Leese GP, Petrie JR, et al. Risk of acute kidney injury and survival in patients treated with Metformin: an observational cohort study. BMC Nephrol. 2017;18:163. doi:10.1186/s12882017-0579-5.

2. Weckmann GFC, Stracke S, Haase A, Spallek J, Ludwig F, Angelow A, et al. Diagnosis and management of nondialysis chronic kidney disease in ambulatory care: a systematic review of clinical practice guidelines. BMC Nephrol. 2018;19:258. doi: 10.1186/s12882-018-1048-5.

3. Inzucchi SE, Bergenstal RM, Buse JB, et al. Management of hyperglycemia in type 2 diabetes, 2015: a patient-centered approach: update to a position statement of the American Diabetes Association and the European Association for the Study of Diabetes. Diabetes Care. 2015;38:140-149. doi: 10.2337/dc14-2441.

4. Bailey CJ, Day C. Diabetes therapies in renal impairment. Br J Diabetes Vasc Dis. 2012;12:167-71. doi: $10.1177 / 1474651412458811$.

5. Asgharpour M, Danialy R, Mirhashemi S, Ebrahimi S. Intravenous contrast agents in diabetic patients taking metformin; an updated review on current concepts. J Nephropathol. 2020;9:e05. doi: 10.15171/jnp.2020.05.

6. Blumenberg A, Benabbas R, Sinert R, Jeng A, Wiener SW. Do Patients Die with or from Metformin-Associated Lactic Acidosis (MALA)? Systematic Review and Meta-analysis of $\mathrm{pH}$ and Lactate as Predictors of Mortality in MALA. J Med Toxicol 2020;16:222-229. doi: 10.1007/s13181-019-007556.

7. Namazi MH, AlipourParsa S, Roohigilani K, Safi M, Vakili $\mathrm{H}$, Khaheshi I, et al. Is it necessary to discontinue metformin in diabetic patients with GFR $>60 \mathrm{ml} / \mathrm{min}$ per $1.73 \mathrm{~m} 2$ undergoing coronary angiography: A controversy still exists?. Acta Biomed. 2018;89:227-232. doi: 10.23750/ abm.v89i2.5446.

8. Cherney DZI, Repetto E, Wheeler DC, Arnold SV, MacLachlan S, Hunt PR, et al. Impact of cardio-renalmetabolic comorbidities on cardiovascular outcomes and mortality in type 2 diabetes mellitus. Am J Nephrol. 2020;51:74-82. doi: 10.1159/000504558.

9. Akhavan Sepahi M, Lakkakula BV, James Kellner S, Valizadeh R. Administration of metformin in type 2 diabetes mellitus patients with chronic kidney disease; facts and myths. J Nephropathol. 2020;9:e04-e. doi: 10.15171/ jnp.2020.04.

10. Lal A, Kaur N, Trivedi N. Metformin, arterial contrast and acute kidney Injury. Acta Biomed. 2019;90:355-356. doi:10.23750/abm.v90i2.8371.

11. Greco P, Regolisti G, Maggiore U, Ferioli E, Fani F, Locatelli C, et al. Sustained low-efficiency dialysis for metforminassociated lactic acidosis in patients with acute kidney injury. J Nephrol. 2019;32(2):297-306. doi: 10.1007/s40620018-00562-2.

12. Wang J, Ai X, Li L, Gao Y, Sun N, Li C, Sun W. Alprostadil protects type 2 diabetes mellitus patients treated with metformin from contrast-induced nephropathy. Int Urol Nephrol. 2017;49:2019-26. doi: 10.1007/s11255-017-16392.

13. Parra D, Legreid AM, Beckey NP, Reyes S. Metformin 
monitoring and change in serum creatinine levels in patients undergoing radiologic procedures involving administration of intravenous contrast media [published correction appears in Pharmacotherapy. 2004;24:1489]. Pharmacotherapy. 2004;24:987-993. doi: 10.1592/ phco.24.11.987.36131.

14. Stades AM, Heikens JT, Erkelens DW, Holleman F, Hoekstra JB. Metformin and lactic acidosis: cause or coincidence? A review of case reports. J Intern Med. 2004;255:179-87. doi: 10.1046/j.1365-2796.2003.01271.x.

15. Cryer DR, Nicholas SP, Henry DH, Mills DJ, Stadel BV. Comparative outcomes study of metformin intervention versus conventional approach the COSMIC Approach Study. Diabetes Care. 2005;28:539-543. doi: 10.2337/ diacare.28.3.539.

16. Salpeter SR, Greyber E, Pasternak GA, Salpeter EE. Risk of fatal and nonfatal lactic acidosis with metformin use in type 2 diabetes mellitus: systematic review and meta-analysis. Arch Intern Med. 2003;163:2594-2602. doi: 10.1001/ archinte.163.21.2594.
17. Rojas LB, Gomes MB. Metformin: an old but still the best treatment for type 2 diabetes. Diabetol Metab Syndr. 2013;5:6. doi: 10.1186/1758-5996-5-6.

18. van der Molen AJ, Reimer P, Dekkers IA, Bongartz G, Bellin MF, Bertolotto M, et al. Post-contrast acute kidney injury. Part 2: risk stratification, role of hydration and other prophylactic measures, patients taking metformin and chronic dialysis patients: Recommendations for updated ESUR Contrast Medium Safety Committee guidelines. Eur Radiol. 2018;28:2856-69. doi: 10.1007/s00330-017-5247-4.

19. Oktay V, Calpar Çıralı İ, Sinan ÜY, Yıldız A, Ersanlı MK. Impact of continuation of metformin prior to elective coronary angiography on acute contrast nephropathy in patients with normal or mildly impaired renal functions. Anatol J Cardiol. 2017;18:334-339. doi: 10.14744/ AnatolJCardiol.2017.7836.

20. Du J, Li R. Can Fundus Fluorescein Angiography be Performed for Diabetic Patients on Oral Metformin?. Chin Med Sci J. 2017;32:119-122. doi: 10.24920/J10019294.2017.015.

Copyright $\odot 2021$ The Author(s); Published by Published by Society of Diabetic Nephropathy Prevention. This is an open-access article distributed under the terms of the Creative Commons Attribution License (http://creativecommons.org/licenses/by/4.0), which permits unrestricted use, distribution, and reproduction in any medium, provided the original work is properly cited. 